\title{
C. Ronald MacKenzie, Charles N. Cornell, Stavros G. Memtsoudis (Eds.): Perioperative care of the orthopedic patient
}

\author{
2014, XVII, 421 p. 72 illus., 25 illus. in color, e-book: 118,99 €-Hardcover: 147,69 €, \\ Springer-Verlag Paris, Berlin, Heidelberg, New York, Hong Kong, Londres, Milan, \\ Tokyo, ISBN 978-1-4614-0100-1
}

\section{Pierre Kehr}

Received: 10 September 2014 / Accepted: 15 September 2014/Published online: 24 September 2014

(C) Springer-Verlag France 2014

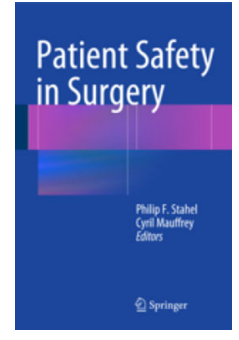

This work is based on the important development of the orthopedic surgery at the twentieth century, making it possible to improve quality of life, the mobility and the lifetime of million patients.

After general considerations on the preoperative state in the first part of the book, the second part is dedicated to anesthetic management. This part analyzes the anesthesia at the orthopedic patient, in the child, the techniques specific to certain operational methods, the postoperative care under the angle of the anesthesia and the treatment of the postoperative pain.

The third part of the book is dedicated to the typical cases, like that of the patients rhumatologic, the patients cardiopathic, insufficient respiratory, of insufficient renal, diabetic, etc. all morbidities in fact are studied under the angle of the anesthesia.

Thirty chapters thus make it possible to treat all the aspects pre, per- and postoperative. Many appendices supplement the various chapters, and a broad final alphabetical index makes it possible to go quickly within for the subjects scanned by the player in a hurry.

Written by many collaborators orthopedic surgeons and anesthetists, this book constitutes a true platform of contact between these two specialities, so often confronted with clinical situations where the operational indication must be discussed according to the anesthetic risk. For these reasons, this book should be present in the office of each specialist, but even be on the table of staff, during the discussion of the operational indications.

P. Kehr ( $\square)$

Strasbourg, France

e-mail: kehrpier@aol.com 